never develops a concave surface on the stone. For that, it is necessary to use an abrasive of large pieces comparable with the marble specimen itself $(3 \mathrm{~cm}$.). Broken flints serve very well and are easy to get. If we put a dozen such in a box with a square slab of marble, the edges and corner of the marble are, of course, rounded, but the large faces become concave.

Another instructive experiment on this subject is to use instead of marble a square of plate glass. If this is abraded in the rotating container with carborundum powder, the edges alone are pitted. This is the initial stage of the ordinary process of forming a rounded pebble. If, on the other hand, we put the glass in the revolving box with a number of sharp flints of size comparable with its own, the sharp edges have chips broken off them, which process represents the first stage of rounding the edge. In addition, we find pitting on the flat polished surface, and these pittings are more concentrated at the middle than at the edges; clearly showing the early stages of the development of a concavity.

With the view of analysing this effect, the experiment was repeated using a single flint only instead of many, and for a longer period, so that the aggregate number of pittings might be comparable. In contrast, these pittings were now found to be uniformly distributed, so that in this case no concave eurvature is produced. It can scarcely be doubted that the stones other than the one which is actually operative act as a shield, and are more likely to screen the outside than the middle of the glass. In this way concavity is produced.

\section{WATER SUPPLIES IN GREAT BRITAIN AND THEIR UTILIZATION}

A JOINT meeting of the Geological Society and the Institution of Water Engineers wais held on April 19, under the chairmanship of Prof. W. G. Fearnsides, to discuss "Water in Relation to Town and Country Planning". As proposed by the chairman in his introduction, the meeting was mainly confined to a consideration of sources of water and their relation to development in Great Britain. The meeting attracted a notable attendance and produced a. vigorous discussion. In addition to Prof. Fearnsides and Mr. S. R. Raffety, chairman of the Institution of Water Engineers, who briefly introduced the discussion on behalf of the water engineers, there were fifteen other speakers. They covered a wide range of topics which will be considered in order, though it may ke noted at the outset that many of the outstanding aspects were indicated by Prof. P. G. H. Boswell in a well-considered opening on kehalf of the geologists.

The vital dependence of populations and industry alike on water supply was inevitably stressed by many speakers. In earlier times no centre of habitation could develop unless water was obviously at hand, but now that it appears from pipes and taps the relation is overlooked with amazing frequency. Apart from their head waters, nearly all streams in Great Britain are polluted beyond any possibility of direct use for domestic and for most industrial purposes. Yet the increasing population must spread, and in certain cases industries must move, largely to areas where local surface supplies are quite unavailable. Hence underground water becomes increasingly important. Prof. Fearnsides gave an apt illustration from the Yorkshire coalfield. The growing exhaustion of the coals in the western part of the field compels the industry and population to move increasingly eastward to the coals buried under the Trias plain. The underground Trias water has been excellent, but growing demand has led to over-pumping; mining fractures the overlying rocks, and the combined result in some cases is the drawing in of water from the underlying Permian or even from the Coal Measures, with great deterioration in quality, as well as actual or threatened insufficiency.

Prof. Boswell particularly stressed the point that industrial requirements continue to increase to such a degree that a single large works may use as much water as a fair-sized town. Many instances of consequent serious difficulty have occurred, and he indicated that industrialists are very grateful for early information regarding the actual condition in areas under consideration. While the geologist may be able to give a fair assessment of a 'virgin' area, great uncertainty may be attached to some already industrialized areas where, though underground water is certainly prolific, there is complete absence of any systematic record of the heavy draughts already made. Mr. H. P. Hill, besides supporting the general theme by reference to the dependence of the older industrial areas of Lancashire and Yorkshire on the head waters of the Pennine rivers, added the valuable point that a substantial proportion of those head waters have long been impounded for the supply of canals which are now disused or decadent. Some of this water could now be used for supply.

Much of the discussion naturally ranged around the question of alternatives when adequate supplies of pure water are not available in the neighbourhood. For the really great centres of population the ultimate solution (with the notable exception of London) has almost inevitably been the use of remote upland waters. But for any smaller centres the cost of such lengthy aqueducts is forbidding. London's great contribution to the problem has been the demonstration that even highly polluted river-water may be rendered particularly pure and distributed by pumping at reasonable economic rates. It certainly points the way to one possible line of advance in certain cases. In his opening comments on the growing south-east Yorkshire towns, Prof. Fearnsides made the interesting suggestion that they may have to resort to constructing reservoirs on the middle courses of the Ouse tributaries, while Prof. W. S. Boulton (in the course of a written contribution) referred to the very considerable areas of the eastern and southern Midlands with little underground water and very variable sluggish rivers. He likewise suggested a substantial development of low-level reservoirs in such areas.

Mr. R. C. S. Walters particularly emphasized the point made by several speakers that great quantities of pure and relatively costly water are wasted, quoting the extreme case of its use for quenching gasworks coke. Like others, he commented on the danger and difficulties of 'dual' supplies of water, but hoped that the engineer might overcome it. In this connexion the use of mine water was considerably debated. Prof. Boulton referred to its extensive use for the supply of canals in the Midlands, and he had investigated its possibility for the many million 
gallons required by the cooling towers of the electric sta tions of the national grid. Unfortunately, many analyses proved it too corrosive, and several speakers quoted similar experience in attempts to promote its ind ustrial use. This prevailing conclusion, however, should not obscure the fact that there are industrial uses for which it would serve; nor the quite different eireumstance that some mines take and contaminate good water from strata overlying the Coal Measures, which could be kept separate and utilized, as is actually done in the case. of large volumes of Magnesian Limestone water tapped by certain mines in Durham.

Prof. Boulton's ultimate proposal for the coolingtower problem was the use of purified sewage effluent, of which Birmingham provides more than 20 million gallons per day. This principle may yet be carried much further. The question of sewage control and purification is quite inseparable from the whole question of water supply in several ways. In Mr. Raffety's opening he referred to the large increase in the volume of sewage water in one area which resulted from the building-up of an adjoining district. Ruinfall which formerly soaked into the land and fed the underground supplies was led into sewers, contaminated, taken away and lost for supply. In large urban areas this leads to a great reduction of underground resources. A later speaker directed attention to the fact that many important wells and boreholes are in the vicinity of rivers, and the underground waters on which they draw are liable to contamination by the polluted streams. There is no reason now why all substantial sewage should not be so treated as to produce a practically pure water. The fact that the cost of treatment cannot be immediately offset by a corresponding profit entry loses all force when weighed against the immeasurable gain to the community in amenities of all kinds, and not least in the protection of its water supplies.

The question of protection was another main theme of the discussion. Mr. R. C. S. Walters demonstrated by the cases of several of the Coventry wells that the area of intake of the underground water may be immediately around the well or in some more or less remote area in particular cases. $\mathrm{He}$ emphasized the need for precise geological knowledge of each case to define the region where protection from surface pollution is necessary. Dr. Buchan illustrated the pollution of the underground supplies which has resulted from the over-pumping in certain parts of east London drawing in salt water from the estuary. Prof. Boswell noted the depletion of considerable areas which results from mine drainage, and Mr. Edmunds the loss from the uncontrolled flow of artesian supplies.

Dr. G. M. Lees quoted his experience of recharging Persian oil-wells with temporary surplus petroleum, which had proved entirely successful, and suggested the replenishment of water supplies from the chalk by leading the excess of pure water available during periods of plenty into suitable disused wells. Though other speakers referred to cases in which attempts had failed, the idea seems worthy of further investigation.

Regarding the important question of water-borne disease, Mr. Raffety noted that while concern is properly felt for the safety of underground supplies in urban areas, the majority of proved cases of epidemics arising from polluted water have concerned supplies from rural sources. Mr. E. Morton observed that while the large undertakers can afford to purchase substantial areas of land or otherwise protect their sources, the smaller rural companies have not this facility. The ever-present danger of unrestricted private pumping is widely felt, and attention was directed to the unknown but probably very considerable remote effects of the concentrated pumping of such prolific areas as the Colne and Lea valleys.

The need for investigation and for the proper recording of all supplies was naturally uppermost in the minds of many speakers. All dwolt on the incompleteness of most records (making them of little value) and the extreme lack of information regarding private supplies. Mr. Edmunds commented on the special value of long-period records and on the unfounded fears which have frequently prevented disclosure of information. Dr. Buchan also gave an admirably illustrated account of some of the more recent studies of underground waterlevels by the Geological Survey, extending over a wider area his well-known studies of the London region, and indicating the importance of such collated knowledge for the correct assessment of the water resources in any area.

Prof. W. B. R. King discussed the fundamental importance of systematically planned research on selected areas, including continuous rainfall and waterlevel data, percolation and run-off gauging, behaviour of exhaustion cones, and investigation of rock characteristics in the field and laboratory. Much might be done by the co-operation of university departments with neighbouring water authorities. Some of the work would be necessarily expensive and funds would be needed.

Sir Malcolm Watson directed attention to a matter of first-class importance in stressing the need of adequate supplies of water for agriculture. Mr. C. Green spoke especially of the part played by finance as the final deciding factor in all water schemes, and the essential ground for Government intervention.

Finally, Mr, C. E. N. Bromehead referred to some recently discovered and quite unexplained anomalies in the iodine content of certain supplies. Though the iodine amounts only to some 50 parts per thousand million, this is about seventeen times the normal, and the occurrences represent a medically important and geologically puzzling problem.

While the meeting did not proceed to the framing of formal resolutions, the vital importance of a comprehensive survey of the water resources of Great Britain, both surface and underground, was made clearly evident; as also the fact that such a survey cannot be satisfactorily complete or just unless it be made under statutory powers. Urgent demand has compelled the great cities to use their large financial resources to solve the water problem, usually by resort to long-distance impounding schemes. Hence the outstanding problems relate chiefly to 'rural' areas and widely spread industrial regions, to which such schemes cannot as a rule be economically applied. For this reason underground waters acquire an everincreasing importance, and the time is overdue for the Government to accept responsibility for the control of water supply. Water supply must be one of the foremost considerations in every scheme of town and country planning. Uncontrolled competition for water cannot be tolerated, whether among private concerns or public companies. It can have only the most harmful results, and it reflects most seriously on those responsible for the orderly development of the country. 